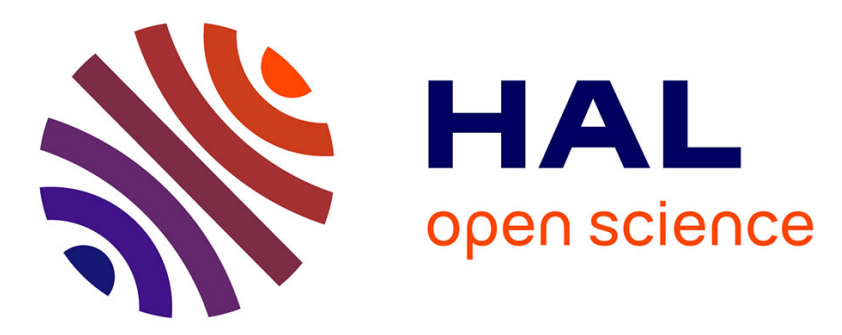

\title{
Influential parameters on electromagnetic properties of nickel-zinc ferrites for antenna miniaturization
}

David Souriou, Jean-Luc Mattei, Alexis Chevalier, Patrick Queffelec

\section{To cite this version:}

David Souriou, Jean-Luc Mattei, Alexis Chevalier, Patrick Queffelec. Influential parameters on electromagnetic properties of nickel-zinc ferrites for antenna miniaturization. Journal of Applied Physics, 2010, 107, pp.09A518. 10.1063/11.3356235 . hal-00488880

\section{HAL Id: hal-00488880 \\ https://hal.univ-brest.fr/hal-00488880}

Submitted on 6 Jun 2016

HAL is a multi-disciplinary open access archive for the deposit and dissemination of scientific research documents, whether they are published or not. The documents may come from teaching and research institutions in France or abroad, or from public or private research centers.
L'archive ouverte pluridisciplinaire HAL, est destinée au dépôt et à la diffusion de documents scientifiques de niveau recherche, publiés ou non, émanant des établissements d'enseignement et de recherche français ou étrangers, des laboratoires publics ou privés. 


\title{
Influential parameters on electromagnetic properties of nickel-zinc ferrites for antenna miniaturization
}

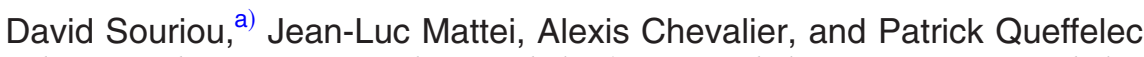 \\ Laboratoire des Sciences et Techniques de l'Information, de la Communication et de la Connaissance \\ (Lab-STICC), UMR CNRS 3192, Université Européenne de Bretagne-U.B.O., 6 avenue Le Gorgeu, \\ CS 93837, 29238 Brest Cedex 3, France
}

(Presented 20 January 2010; received 27 October 2009; accepted 1 December 2009; published online 6 May 2010)

\begin{abstract}
Electromagnetic properties of nickel-zinc ferrites based materials make them potential candidates for applications linked to telecommunications. In the present study, nanosized particles of spinel ferrite $\mathrm{Ni}_{0.5} \mathrm{Zn}_{0.3} \mathrm{Co}_{0.2} \mathrm{Fe}_{2} \mathrm{O}_{4}$ were prepared by coprecipitation method. An optimized material is obtained after adequate heat treatment and partial filling of the porosity by epoxy resin. This material lies between ceramic and composite medium (with porosity close to 40\%), and shows almost constant complex permeability and permittivity in the frequency range from $0.1-0.7 \mathrm{GHz}$, and equal to $\sim 3.5$-j0.15 (loss tangent $\sim 0.04$ ) and $\sim 4$-j0.2 (loss tangent $\sim 0.02$ ), respectively. The refractive index $\mathrm{n}$ is close to 3.75 . These electromagnetic properties, in particular the low levels of losses, show that this material could be useful to the design of miniaturized antennas in the VHF-uhf (300-700 MHz) range of frequency. (C) 2010 American Institute of Physics.
\end{abstract}

[doi:10.1063/1.3356235]

\section{INTRODUCTION}

The tremendous development of handheld terminals in the low uhf range $(300-700 \mathrm{MHz})$ asks for antennas of reduced physical dimension without affecting their electromagnetic performances. ${ }^{1-4}$ Actually, present antennas are too large to allow satisfactory integration into such devices, and the present techniques used to reduce their size degrade the performances of the antennas. ${ }^{5}$ Materials with low dielectric and magnetic loss tangents are very useful to the design of miniaturized antennas and simultaneously maintaining the electrical dimensions (the electrical length is the product between the geometrical length of the medium with its refractive index). Actually, materials that show sufficiently low magnetic and dielectric loss tangents $\left(\operatorname{tg} \delta_{\mu}=\mu^{\prime \prime} / \mu^{\prime}\right.$ and $\left.\operatorname{tg} \delta_{\varepsilon}=\varepsilon^{\prime \prime} / \varepsilon^{\prime}<5 \times 10^{-2}\right)$ and a refractive index $\left(\mathrm{n}=\sqrt{\mu^{\prime} \varepsilon^{\prime}}\right)$ large enough, could be useful to the design of antennas with reduced physical dimensions ( $\mu^{\prime}$ and $\varepsilon^{\prime}$ are real parts of relative permeability and permittivity, respectively, and $\mu^{\prime \prime}$ and $\varepsilon^{\prime \prime}$ are the imaginary parts). To achieve low-loss requirement, the material must have a resonant frequency far from the desired frequency band. Co-substituted NiZn ferrites are promising magnetic materials for radiofrequency applications, i.e., upto $300 \mathrm{MHz}{ }^{6}$ Recent studies show results for antenna miniuaturization at lower frequencies. ${ }^{2,3,7}$ However, it is not usual to use spinel ferrites for microwave devices. Our task is concerned with soft magnetic material-spinel ferrite that would show potentiality to be used in the frequency range $300-0.7 \mathrm{GHz}$.

This paper will show how the electromagnetic properties of the final substrate are influenced-for the chosen composition - by the heat treatment (calcination and sintering) and also by filling of the porosity of the sample.

\footnotetext{
${ }^{a)}$ Electronic mail: souriou.david@wanadoo.fr.
}

\section{EXPERIMENTAL PROCEDURE}

$\mathrm{Ni}-\mathrm{Zn}-\mathrm{Co}$ ferrites nanopowders of composition $\mathrm{Ni}_{0.5} \mathrm{Zn}_{0.3} \mathrm{Co}_{0.2} \mathrm{Fe}_{2} \mathrm{O}_{4}$ (labeled $\mathrm{J} 2$ powder) were prepared via the conventional coprecipitation method. ${ }^{8}$

First high purity raw materials, nickel chloride, cobalt chloride, zinc chloride, and iron (III) chloride were taken from their molar solution in accurate stoichometric proportions. These solutions were poured into boiling solution of $\mathrm{NaOH}(0.45 \mathrm{~mol} / \mathrm{l})$ under stirring $(\sim 350 \mathrm{rpm})$. After coprecipitation, $p \mathrm{H}$ is set between 11.5 and 12 , which we found to be the optimum $p \mathrm{H}$ for stoichometric precipitation. Reaction is continued for $30 \mathrm{~min}$ at temperature $100{ }^{\circ} \mathrm{C}$, the suspension is cooled to ambient temperature and is then centrifuged at $6000 \mathrm{rpm}$ for $13 \mathrm{~min}$ after sedimentation. The residue is dried in an electrical oven before to be calcinated (temperature $\mathrm{T}_{\mathrm{c}}=650$ or $800{ }^{\circ} \mathrm{C}$ ) in air for $3 \mathrm{~h}$ (with heating and cooling rates of $200{ }^{\circ} \mathrm{C} / \mathrm{h}$ ) to obtain a ferrite powder. The average particle size was $25 \mathrm{~nm}$ before the calcination stage (transmission electron microscopy observation). The density of the powder is measured by a helium picnometer.

Then this powder was compacted by uniaxial pressing (applied pressure: $325 \mathrm{MPa}$ ) into a torroidal shape, chosen for its convenience for electromagnetic characterization by using the coaxial line-based method. The final ferrite body was obtained after sintering in air (temperature $T_{S}=900$ or $1000{ }^{\circ} \mathrm{C}$ ) for $1 \mathrm{~h}$ at a heating rate of $300{ }^{\circ} \mathrm{C} / \mathrm{h}$ and were subsequently cooled at a cooling rate of $600{ }^{\circ} \mathrm{C} / \mathrm{h}$ to room temperature. These temperature profiles were optimized with the help of differential thermal analysis. The density of our samples is determined by measurement of their dimensions (results shown in Table I).

A Hewlett Packard HP 8753ES network analyzer setup was used for the measurements of the sample parameters $\varepsilon$ (complex permittivity $\varepsilon^{\prime}$-j $\varepsilon^{\prime \prime}$ ) and $\mu$ (complex permeability $\left.\mu^{\prime}-\mathrm{j} \mu^{\prime \prime}\right)$ over a wide range of frequencies (10 MHz-6 GHz). 
TABLE I. Samples density as a function of heat treatments (powder density, $\left.5.113 \mathrm{~g} \mathrm{~cm}^{-3}\right)$.

\begin{tabular}{ccc}
\hline \hline $\begin{array}{c}\text { Calcination temperature } \\
\left({ }^{\circ} \mathrm{C}\right)\end{array}$ & $\begin{array}{c}\text { Sintering temperature } \\
\left({ }^{\circ} \mathrm{C}\right)\end{array}$ & $\begin{array}{c}\text { Density } \\
(\%)\end{array}$ \\
\hline 650 & 900 & 73.12 \\
800 & 900 & 57.34 \\
650 & 1000 & 87.71 \\
\hline \hline
\end{tabular}

\section{RESULTS AND DISCUSSION}

\section{A. Influence of the temperature of calcination \\ 1. Calcination of the green body}

Real and imaginary parts of permeability and permittivity of two $\mathrm{J} 2$ samples (calcinated at $\mathrm{T}_{\mathrm{C}}=650{ }^{\circ} \mathrm{C}$ and $800{ }^{\circ} \mathrm{C}$, respectively) show the sensitivity of the electromagnetic properties to the value of $\mathrm{T}_{\mathrm{C}}$ [Figs. 1(a) and 1(b)]. The main result is a drastic decrease in dielectric losses between 650 and $800{ }^{\circ} \mathrm{C}$. A slight $(10 \%)$ increase of $\mu^{\prime}$ below $1 \mathrm{GHz}$ is associated to a shift of $\mu^{\prime \prime}$ to lower frequencies as expected from Snoek's law. ${ }^{9}$

\section{Influence on the calcination temperature on sintering}

Both $\mathrm{J} 2$ samples were sintered at $\mathrm{T}_{\mathrm{S}}=900{ }^{\circ} \mathrm{C}$ [Figs. 2(a) and 2(b)]. Here two salient results are underlined. First, whatever the value of $T_{C}$ the real permeability of both samples reaches a same value after sintering. Second, the real permittivity of the sample calcinated at $\mathrm{T}_{\mathrm{C}}=800{ }^{\circ} \mathrm{C}$ re-

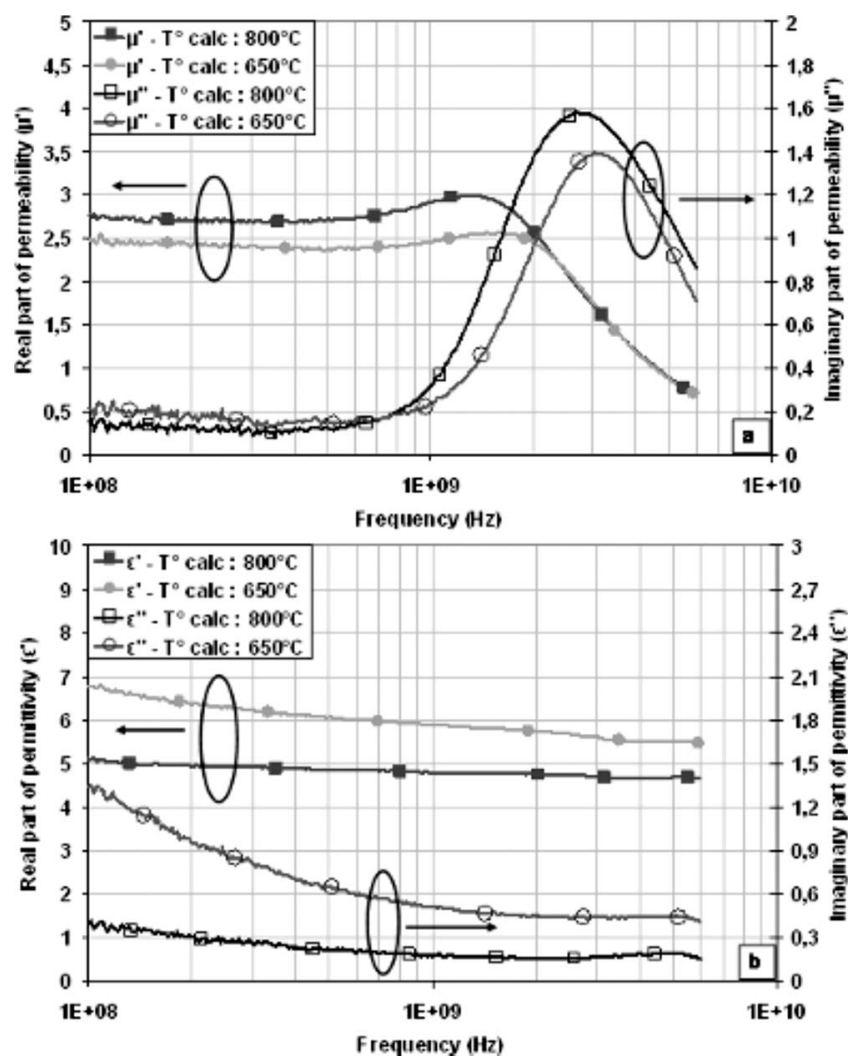

FIG. 1. Measured permeability (a) and permittivity (b) spectra of the calcinated green body. mains unchanged by sintering at $\mathrm{T}_{\mathrm{S}}=900{ }^{\circ} \mathrm{C}$, whereas that of the sample calcinated at $\mathrm{T}_{\mathrm{C}}=650{ }^{\circ} \mathrm{C}$ is strongly decreased.

These experimental data can be roughly understood as follows. For a calcinating process that occurs at $\mathrm{T}_{\mathrm{C}}$ $=800{ }^{\circ} \mathrm{C}$, the sintering process actually starts, then a network of necks of matter between grains is achieved. ${ }^{10}$ This leads to a more heterogeneous grain size distribution. Consequently, the resonance peak is broader and the magnetic losses higher at lower frequencies. Owing the aimed applications, $\mathrm{T}_{\mathrm{C}}=650{ }^{\circ} \mathrm{C}$ is the calcination temperature that will be held.

\section{B. Influence of the sintering temperature}

Starting from $\mathrm{J} 2$ powder previously calcinated at $650{ }^{\circ} \mathrm{C}$, two samples were sintered at $\mathrm{T}_{\mathrm{S}}=900{ }^{\circ} \mathrm{C}$ and $\mathrm{T}_{\mathrm{S}}$ $=1000{ }^{\circ} \mathrm{C}$, respectively. The real part of permeability increases with the sintering temperature [Fig. 3(a)], whereas the maximum of $\mu^{\prime \prime}$ shift to low frequency according to Snoek's law again. ${ }^{9}$ The densification by sintering occurs in three steps as follows: bridge formation between grains, granular rearrangement, and then grain growth. ${ }^{10}$ The width of the resonance peak is notably increased by high sintering temperature $\left(1000{ }^{\circ} \mathrm{C}\right)$, this can be linked to grain growth. The observed decreases of $\varepsilon^{\prime}$ and $\varepsilon^{\prime \prime}$ with increasing $\mathrm{T}_{\mathrm{S}}$ [Fig. 3 (b)] is also a marker of a reduced porosity. Dielectric looses are appreciably reduced when $\mathrm{T}_{\mathrm{S}}=1000{ }^{\circ} \mathrm{C}$, due to a shrinkage of porosity that decreases area effects.

Low magnetic losses and satisfactory optical index are then obtained with $\mathrm{J} 2$ powder calcinated at $\mathrm{T}_{\mathrm{C}}=650{ }^{\circ} \mathrm{C}$ and
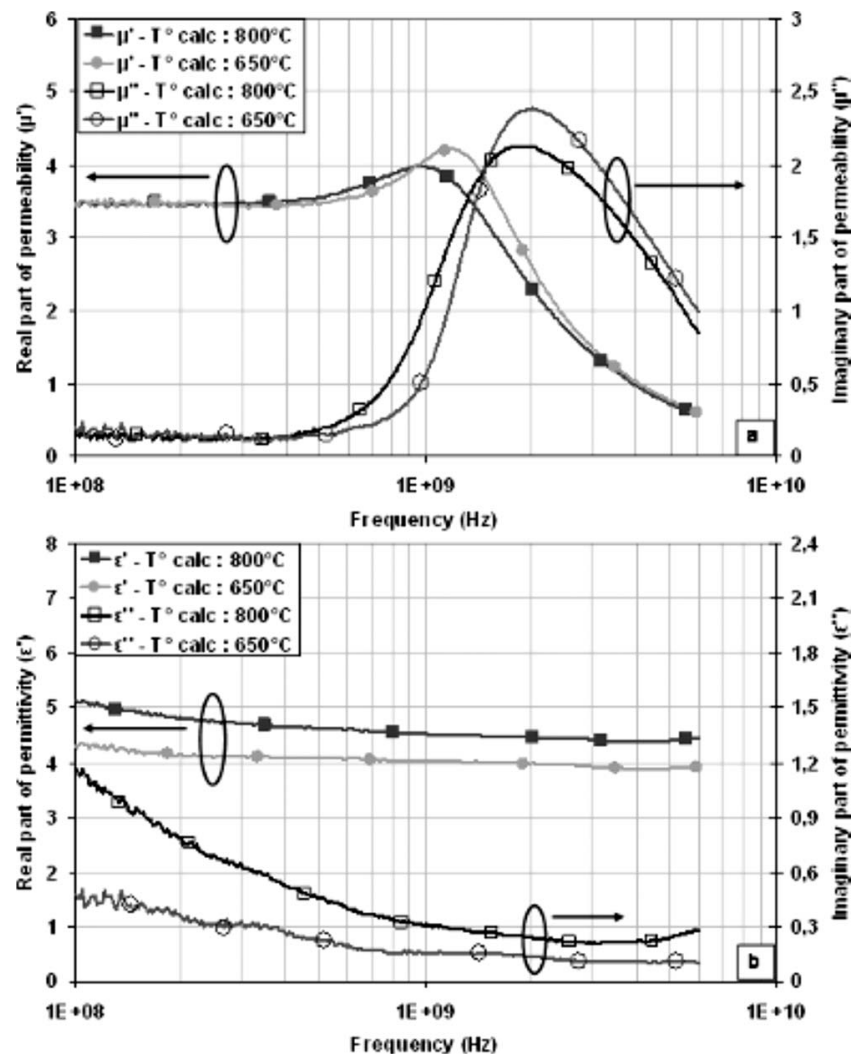

FIG. 2. Measured permeability (a) and permittivity (b) spectra after calcination and sintering $\left(\mathrm{T}_{\mathrm{S}}=900{ }^{\circ} \mathrm{C}\right)$. 


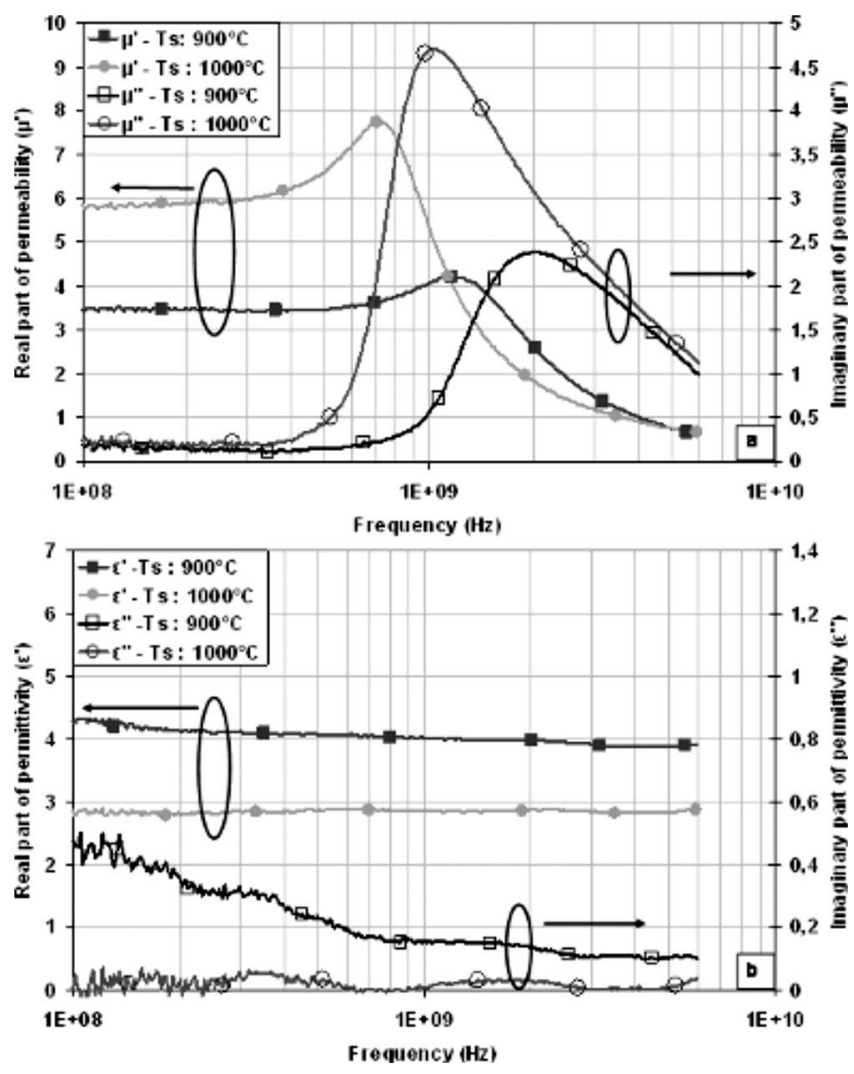

FIG. 3. Measured permeability (a) and permittivity (b) spectra after calcination at $650{ }^{\circ} \mathrm{C}$ and sintering.

sintered at $\mathrm{T}_{\mathrm{S}}=900{ }^{\circ} \mathrm{C}$. However, dielectric losses $\operatorname{tg} \delta_{\varepsilon^{\prime}}$, remain too high for the envisaged applications.

\section{Influence of soaking}

In order to get a reduced $\operatorname{tg} \delta_{\varepsilon^{\prime}}$ the samples are afterwards immersed into a solution of epoxy resin dissolved in acetone and dried. A fraction of voids is filled by the resin, and the global porosity of the sample is lowered (Table II). The measured permittivity and permeability are shown on Fig. 4. A noteworthy fall down of $\varepsilon^{\prime \prime}$ promotes the so obtained material as a suitable one for antenna miniaturization in the frequency range $100-700 \mathrm{MHz}$.

\section{CONCLUSION}

Our experiments have shown that electromagnetic properties of ferrites are influenced by several parameters. For a nanometric powder elaborated by coprecipitation, the calcination and the sintering temperatures must be chosen so that the final material fits desired electromagnetic requirements for the reduction of antenna size.

The heat treatment submitted to the studied ferrite powders leads to a porous material with high ferrite content that

TABLE II. Measured electromagnetic parameters (frequency range 100-700 $\mathrm{MHz}$ ) after soaking with epoxy resin (amount of filled porosity: 21\%).

\begin{tabular}{lccc}
\hline \hline & $\operatorname{tg} \delta_{\varepsilon}=\varepsilon^{\prime \prime} / \varepsilon^{\prime}$ & $\operatorname{tg} \delta_{\mu}=\mu^{\prime \prime} / \mu^{\prime}$ & $\sqrt{\mu^{\prime} \varepsilon^{\prime}}$ \\
\hline Before soaking & $0.043-0.115$ & $0.054-0.067$ & $3.75-3.90$ \\
After soaking & $0.015-0.046$ & $0.048-0.064$ & $3.64-3.75$ \\
\hline \hline
\end{tabular}
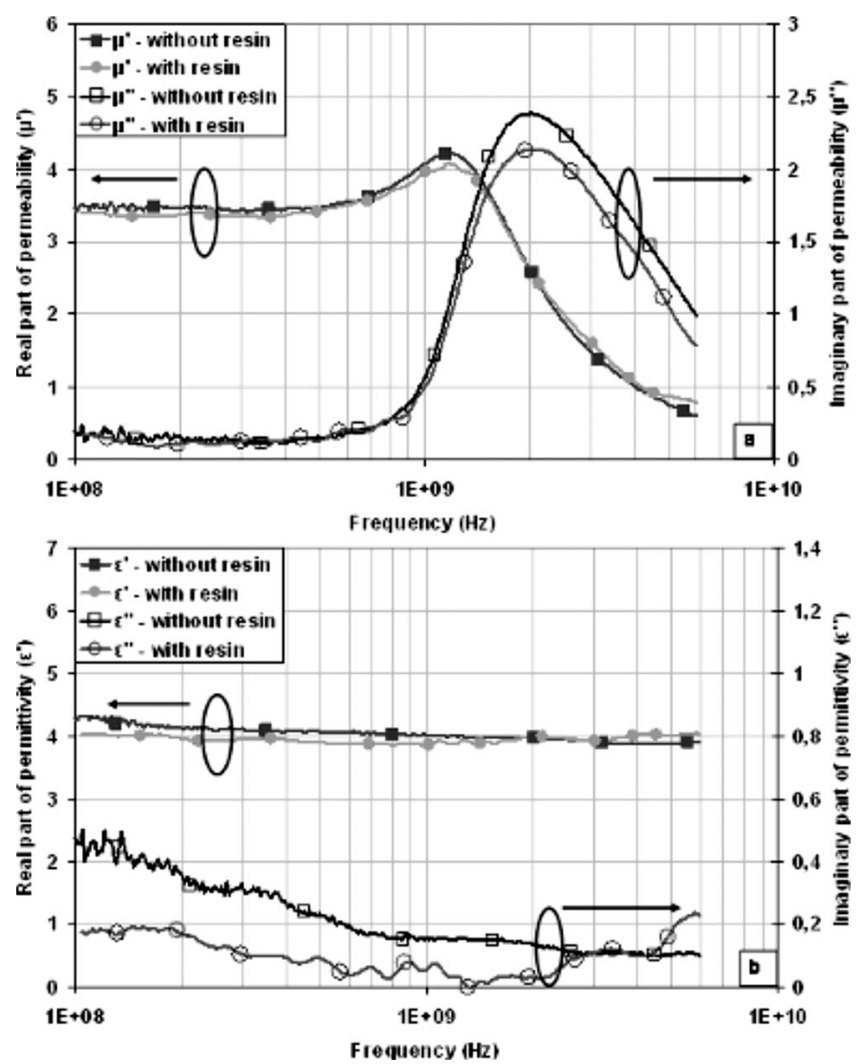

FIG. 4. Measured permeability (a) and permittivity (b) spectra after heat treatment $\left(\mathrm{T}_{\mathrm{C}}=650{ }^{\circ} \mathrm{C}, \mathrm{T}_{\mathrm{S}}=900{ }^{\circ} \mathrm{C}\right)$ followed by soaking with epoxy resin.

can be considered to lie in the intermediate state between the sintered ferrite and the composite. Then, we take advantage of the composite character of the obtained ceramic sample to get ferrite with satisfactory permeability and permittivity levels at unusual high resonance frequency for soft ferrites.

A striking point in the presented data is the low level of magnetic (and dielectric) loss tangents on a wide frequency range, which clearly distinguish our results.

\section{ACKNOWLEDGMENTS}

This work was supported by the Agence Nationale pour la Recherche (ANR-NAOMI project).

${ }^{1}$ H. Mosallaei and K. Sarabandi, IEEE Trans. Antennas Propag. 52, 1558 (2004).

${ }^{2}$ S. Bae, Y. K.Hong, and A. Lyle, J. Appl. Phys. 103, 07 E929 (2008).

${ }^{3}$ I. Kim, S. Bae, and J. Kim, J. Korean Phys. Soc. 52, 127 (2008).

${ }^{4}$ K. Buell, H. Mossallaei, and K. Sarabandi, IEEE Trans. Microwave theory Tech. 54, 135 (2006).

${ }^{5}$ J. Holopainen, J. Villanen, M. Kyro, C. Icheln, and P. Vainikainen, Antenna Technology Small Antennas and Novel Metamaterials, Proceedings of IEEE International Workshop, March 6-8, 2006 (unpublished), pp.305308.

${ }^{6}$ R. Lebourgeois, J. Ageron, H. Vincent, and J.-P. Ganne, Proceedings of the ICF, Vol. 8, Kyoto (Japan) (2000), p. 373.

${ }^{7}$ L. Z. Wu, J. Ding, H. B. Jiang, C. P. Neo, L. F. Chen, and C. K. Ong, J. Appl. Phys. 99, 083905 (2006).

${ }^{8}$ P. Mathur, A. Thakur, and M. Singh, J. Magn. Magn. Mater. 320, 1364 (2008).

${ }^{9}$ A. N. Lagarkov and K. N. Rozanov, J. Magn. Magn. Mater. 321, 2082 (2009).

${ }^{10}$ R. Valenzuela, "Magnetic Ceramics" (Cambridge University Press, Cambridge, UK, 1994). 